Human Ethology Bulletin 31 (2016)3: 1- 4

Letter from the Editorial Board

\title{
BETWEEN PHENOMENA AND SCIENCE
}

\section{Elisabeth Oberzaucher Editor in Chief}

Phenomena are defined as things that manifest themselves and are understood as accessible to sensory perception. This is as far as the relation between phenomena and humans goes in its basic definition. There are no higher cognitive processes required to manifest a phenomenon. What does this mean?

In visual perception, sensory and cognitive processes act in concert to translate light patterns into visually perceived objects. Light is focussed through the cornea and the lens of the eye and directed toward the retina. The retina translates the light stimuli into electric signals. The retina itself already processes the input through complex enhancing and suppressing interactions of the receptor cells. These result in enhanced contrast, and movement detection. This means that the signals communicated from the retina towards the brain are already an interpretation of the original light stimulus, and thus a deviation from the original phenomenon. Further integration and interpretation happens in the visual cortex, resulting in the cognitive event we call visual perception.

What we perceive of our surroundings is the result of a complex interplay between the physical events in our environment and our sensory and cognitive apparatus. Therefore, our perception of phenomena is not objective in itself. Our senses and our brains are optimised for the interaction with a meso-cosmos, which contains most of what is relevant to our biological needs. Both in the micro- as in the macro-cosmos we are less well equipped. On the micro-level, we are mostly aware of our senses' limitations constraining our ability to perceive our physical environment, whereas on the macro-level the limits are mostly posed by our cognitive capacities.

Since phenomena are beyond our capacities to explain and understand, they do not remain static. Their very existence as phenomena ends when there is a scientific explanation. Scientific explanations can be given on different levels.

Nikolaas Tinbergen (1951) defined the four questions that should provide guidance for a behavioural scientist and that need to be addressed to understand behaviour. These four 
questions are the central ones for biological research. They ensure that we do not lose sight of the bigger picture.

The question addressing proximate mechanisms deals with the physiological mechanisms that govern behaviour. The question addressing proximate causes looks into ontogenetic issues. The question addressing the ultimate function analyses the adaptive value, and the question addressing ultimate causes investigates how it came about in the course of evolution.

For decades these questions have provided invaluable guidance in ethological sciences. With increasing understanding of concepts and sophistication of our methodologies the way how Tinbergen's questions affect our research today has changed, nonetheless they have remained central for ethological thinking (Barrett \& Stulp, 2013; Fisher, 2013; Hladky \& Havlicek, 2013; Roberts, 2013; Stephen, 2013; Weisfeld \& Weisfeld, 2013).

Since lack of knowledge is the source of insecurities, we tend to overestimate our knowledge even in areas where our expertise is limited. Our pursuit of answers also leads to a general overestimation of the explanatory power of science. Therefore it is of little surprise that the explanatory power of scientific studies is often exaggerated. At the same time, science increasingly faces criticism: Insights that have been understood as scientific facts for a long time fail to replicate. Studies produce contradictory results. Our everyday experience is incongruent with scientific findings. How shall scientists and laypeople deal with this situation? While science increases knowledge and furthers our understanding of how things work, it rarely ever produces definitive answers. Especially in behavioural sciences, we are acutely aware of our results never being black and white, but characterised by likelihoods and distributions.

Differentiated reporting of such results often requires more time and space than is usually reserved for science news. This is why we all have to work out for ourselves how scientific findings impact our lives and how they should affect our decisions. While every bit of additional information will improve the quality of informed decisions, the decision making process itself gets increasingly complicated. The growing number of relevant factors affects our lives not equally, so we also have to weigh their respective impact.

Coming to informed decisions based on complex interactions requires resources and time. Therefore it is sometimes adaptive to forego the differentiated weighing of all factors, simply because this would be impossible due to the sheer number of decisions we have to make. For many decisions in the course of our regular life we rely on our intuition and do not go beyond a phenomenal perception of our environment. This fast and frugal decision making algorithm is invaluable to get us through the small decisions we make day in day out. For bigger concerns that affect our life in a global way, a more sophisticated approach is advised: Our standing on politics, sustainability, or life goals should be based on informed processing of the complex interactions of the known factors involved. They then constitute a solid framework that guides the quick decision algorithms. Additional information can modify this framework. Using novel knowledge to continuously adapt our decision framework is central for a functional organism. The ability to adapt to permanently changing 
conditions and challenges is probably the main reason for the success of Homo sapiens as a species.

Our cognitive mechanisms correspond to this: Daniel Kahnemann (2012) describes in his book "Thinking, fast and slow" how our reasoning seems to happen in two forms: Dealing with phenomena, when data is sparse and knowledge about interdependencies is missing, system one is employed. It is fast and emotional and results in quick, automated and unconscious decisions. It can compensate very well for gaps in our knowledge, resulting in decisions irrespective of the quality of data they are based on. System one thus prevents us from inertia due to lacking knowledge, but is error-prone due to its overruling ignorance. System two is much slower in its conscious weighing of known facts. Most of our decisions are taken care of by system one; only a small selection of problems is presented to system two. Our brain's tendency to remain on a phenomenological level in most of its decision processes employing simple heuristics makes us vulnerable to committing certain errors. Our difficulties to think in likelihoods and distributions, rather than in categories, are rooted in the dominance of system one. We have to consciously employ system two in order to gain a deep understanding of the complex interactions of the world we live in.

The limitations of the human cognitive apparatus become apparent when we look at the ontogenetic development. Below the age of five, children cannot differentiate between their own knowledge and that of others. They do not possess a Theory of Mind, which constitutes the ability to assess the knowledge of others (Barrett \& Richert, 2003). At this age, children also very much think teleological, i.e. they assume that things are there for a purpose: Clouds are there so it will rain, and it rains so plants can grow. (Kelemen \& DiYanni, 2005). In this respect, children are the perfect believers, as they automatically fill gaps in their cognitive models with introducing some supernatural power (Voland, 2009). The great power of religions lies in their ability to provide simple explanations for phenomena that exceed our cognitive and scientific abilities. This is probably the reason for the ubiquity of religions: Our failure to explain things is psychologically taxing. Through the introduction of supernatural powers, we can get a hold on things that exceed rational and scientific explanations. Without the introduction of a supernatural power we have to accept that there are things that have to remain phenomena for the moment, an unsolved puzzle, a source of insecurity. Religion thus provides a tranquilizing effect for our mind that wants to explain everything.

Acknowledgement of phenomena and the acceptance of the existence of things beyond the borders of our explanatory power require an open, mature mind and the willingness to accept the uncomfortable insecurity of not knowing.

This is where the adventure of science begins.

\section{REFERENCES}


Barrett J., Richert R.A. (2003). Anthropomorphism or preparedness? Exploring children's God concepts. Review of Religious Research 44:300-312. DOI

Barrett, L. \& Stulp, G. (2013). Four more reasons why ethology matters: Tinbergen and the human sciences. Human Ethology Bulletin, 28(4), 39-49

Fisher, M. L. (2013). Tinbergen's influence on advances in female intrasexual competition research. Human Ethology Bulletin, 28(4), 23-30

Hladký, V. \& Havlíček, J. (2013). Was Tinbergen an Aristotelian? Comparison of Tinbergen's Four Whys and Aristotle's Four Causes. Human Ethology Bulletin, 28(4), 3-11

Stephen, I. D. (2013). On aims and methods of facial attractiveness research: the lasting influence of Tinbergen (1963). Human Ethology Bulletin, 28(4), 31-38

Tinbergen, N. (1963). On aims and methods of ethology. Zeitschrift fur Tierpsychologie, 20, 410433. doi: $10.1111 /$ j.1439-0310.1963.tb01161.x reprinted DOI

Weisfeld, C. C. \& Weisfeld, G. E. (2013). Defining normal on the playground: What would Tinbergen do? Human Ethology Bulletin, 28(4), 12-22

Kahneman, D. (2011). Thinking Fast and Slow. Farar, Straus and Giroux. ISBN 978, ISBN 9780374275631 .

Kelemen D., DiYanni C. (2005). Intuitions about origins: Purpose and intelligent design in children's reasoning about nature. Journal of Cognition and Development 6:3-31. DOI

Tinbergen N. The Study of Instinct. Oxford, Clarendon Press, 1951 